\title{
Triangulação entre métodos na administração: gerando conversações paradigmáticas ou meras validações "convergentes"?
}

\author{
Juliana Cristina Teixeira \\ Universidade Federal de Minas Gerais \\ Marco César Ribeiro Nascimento \\ Universidade Federal de São João del-Rei \\ Alexandre de Pádua Carrieri \\ Universidade Federal de Minas Gerais
}

\begin{abstract}
O objetivo deste artigo é buscar responder à seguinte questão: a triangulação como método tem sido utilizada nas pesquisas em administração de uma perspectiva multiparadigmática, gerando conversações entre paradigmas? Ou tem sido utilizada simplesmente no intuito de se realizar uma validação "convergente" entre os métodos na pesquisa? Para responder à questão, utilizou-se o banco de dados referente a 174 artigos que utilizaram a triangulação em três anais do EnAnpad. Esses artigos foram analisados qualitativamente para verificar de que forma a triangulação foi conduzida, a fim de investigar se a combinação se ateve apenas no nível do método, ou se atingiu o âmbito paradigmático. O posicionamento adotado pelos pesquisadores neste estudo é o de defender a importância da conversação paradigmática para lidar com os fenômenos sociais característicos das pesquisas em administração. Os resultados demonstraram que a combinação de métodos tem sido adotada principalmente no intuito de validação convergente, não implicando necessariamente conversações efetivas entre diferentes visões de mundo e de conhecimento científico. O que se observa é sua aplicação principalmente em estudos nos quais predomina, em termos epistemológicos, uma visão positivista e, em termos metodológicos, uma postura nomotética.
\end{abstract}

Palavras-chave: triangulação; métodos; administração; paradigmas; validação convergente.

Triangulation method in administration studies: generating conversations between paradigms or mere "convergent" validations?

The aim of this paper is to answer the following question: the triangulation method has been used in administration researchs from a multiparadigmatic perspective, generating conversations between

Artigo recebido em out. 2010 e aceito em jul. 2011.

RAP - Rio de Janeiro 46(1):191-220, jan./fev. 2012 
paradigms? Or it has been used simply in order to perform a "convergent" validation between the methods? To answer this question, we used a database with 174 papers of three Annals of EnAnpad that used the triangulation. These papers were analyzed qualitatively to verify how the triangulation was conducted to investigate whether the combination was only at the method level, or if it reached at the paradigm level. The position adopted by the researchers in this paper is one that defends the importance of paradigmatic conversation for dealing with social phenomena that are characteristic in researchs in administration. The results showed that combination of methods has been adopted mainly in the purpose of convergent validation without discussions between different worldviews and different scientific knowledge views. What is noticed is its application mainly in studies which predominates, in epistemological terms, a positivist view and, in methodological terms, a nomothetic approach.

KEY WORDS: triangulation; method; administration; paradigms; convergent validation.

\section{Introdução}

O objetivo deste artigo é buscar responder à seguinte questão: a triangulação como método tem sido utilizada nas pesquisas em administração de uma perspectiva multiparadigmática, gerando conversações entre paradigmas? Ou tem sido utilizada simplesmente no intuito de se realizar uma validação "convergente" entre os métodos na pesquisa?

Este artigo é fruto de um processo reflexivo do fazer pesquisa, tendo sua origem em estudos realizados anteriormente. ${ }^{1}$ Nesses estudos, os autores discutiram o tema da triangulação metodológica como caminho possível para o multiparadigmatismo nas pesquisas em administração, defendendo a importância de ambos os temas diante da crescente complexidade dos fenômenos a serem estudados (Teixeira e Nascimento, 2010; Teixeira, Antonialli e Nascimento, 2010; Teixeira, Nascimento e Antonialli, 2010). Segundo esses autores, devese reconhecer a importância da triangulação entre métodos e do multiparadigmatismo, que surgem como tentativa de ampliar as possibilidades de resolução de complexos problemas de pesquisa na área de administração. Os pesquisadores, como apontou Reed (2007) ao introduzir o Handbook de estudos organizacionais, devem estar abertos a novas concepções teóricas e metodológicas, buscando ampliar a própria limitação do conhecimento científico.

Nos estudos, os autores acima mencionados constataram, em análise bibliométrica, que "a incidência da triangulação metodológica é muito pequena comparativamente ao volume de artigos publicados nos anais do EnAnpad" (Teixeira e Nascimento, 2010:12) — Encontro da Associação Nacional de Pós-Graduação e Pesquisa em Administração. Mais precisamente, em 2.853 artigos publicados em três anais do evento (2007, 2008 e 2009), verificou-se que apenas 6\% (174) dos artigos tinham uma triangulação entre métodos em suas pesquisas,

\footnotetext{
${ }^{1}$ Os autores agradecem as contribuições dos debatedores dos artigos anteriores no IV EnAPG (2010) e no XXXIV EnAnpad (2010), respectivamente. As provocações que fizeram à autora Juliana Cristina Teixeira é que a levaram a pensar a utilização da triangulação meramente no sentido de validação convergente.
} 
índice este caracterizado como baixo para os autores, diante das potenciais contribuições da triangulação para as pesquisas.

Como observaram esses autores, apenas 174 artigos entre os 2.853 publicados fizeram o uso da triangulação de métodos. No universo desses 174 artigos, a distribuição percentual por divisões acadêmicas do evento demonstrou ainda que a maior parte desses 174 artigos era da divisão de Administração Pública e Gestão Social (APS). Como decorrência desse resultado, Teixeira, Nascimento e Antonialli (2010:13), analisando de forma mais específica os temas nos quais a triangulação tem sido utilizada nessa área (sendo os principais a relação entre a gestão pública e as funções gerenciais; a gestão de serviços públicos e os novos arranjos institucionais), chegaram à reflexão de que "a triangulação tem sido utilizada, como se indica sua aplicabilidade, para o tratamento de questões complexas no âmbito da Administração Pública".

Outrossim, na literatura especializada, observa-se que a triangulação pode ser tratada também como simples validação convergente entre métodos. Observa-se que tal concepção vai justamente contra a noção de triangulação como associada ao multiparadigmatismo. Pelo contrário, aceita a pesquisa qualitativa de forma "desconfiada", como se a mesma necessitasse de uma validação para que suas implicações fossem científicas, o que descaracteriza sua defesa como estando associada ao multiparadigmatismo, como o fazem os estudos mencionados (Teixeira e Nascimento, 2010; Teixeira, Antonialli e Nascimento, 2010; Teixeira, Nascimento e Antonialli, 2010).

Para responder a questão inicial deste trabalho, utilizou-se o banco de dados referente aos 174 artigos que utilizaram a triangulação nos três anais referidos do EnAnpad. Esses artigos foram analisados qualitativamente para verificar de que forma a triangulação foi conduzida, a fim de investigar se a combinação se ateve apenas ao nível do método, ou se atingiu o âmbito paradigmático. Ou seja, os autores trabalharam com diferentes modos de se ver a realidade em suas pesquisas?

Como pressuposto, considera-se que a busca por uma validação convergente possa, em alguns casos, estar muito mais associada à busca por rigor metodológico, confiabilidade e validade da pesquisa, na dimensão em que tais aspectos são buscados dentro do paradigma positivista de pesquisa. Ou seja, pesquisas que poderiam ser caracterizadas como estando contribuindo para a combinação de múltiplas perspectivas poderiam estar, na verdade, reforçando pressupostos do paradigma positivista, o que ressalta a importância de se analisar a extensão na qual a triangulação é ou não aplicada.

Por fim, ressalta-se que o posicionamento adotado pelos pesquisadores neste estudo é o de defender a importância da conversação paradigmática para lidar com os fenômenos sociais característicos das pesquisas em administração. Corroborando com este posicionamento, Ottoboni (2009:1) defende que

[...] na Administração, diferentemente das ciências naturais, não há a substituição de um paradigma por outro; ela é multidisciplinar e como tal comporta a presença de múltiplos paradigmas. $\mathrm{O}$ avanço da Administração como ciência depende da sua habilidade em encontrar seu próprio 
caminho epistemológico. Esta evolução só será possível quando pesquisadores acreditarem na perspectiva multiparadigmática.

A defesa pelo multiparadigmatismo na administração ganhou também um reforço de Lima (2011), em artigo publicado na RAC — Revista de Administração Contemporânea. O autor problematiza que "a discussão dos paradigmas que regem a produção de conhecimento na administração, [...] mostra evidências de que muitos de seus debatedores perdem partes significativas da questão, por se dedicarem à defesa de um paradigma em particular" (Lima, 2011:199). Nesse sentido, o autor defende que os paradigmas se complementam e que nenhum deve ser abandonado por causa de sua incompletude.

O autor faz, ainda, uma analogia com o desenvolvimento da indústria de aviação para se pensar a complexidade envolvida em pesquisas multiparadigmáticas, relacionando seus benefícios com as dificuldades que as acompanham.

[...] ainda que os aviões estejam sujeitos a quedas e a destruições aterradoras, o imenso benefício proporcionado pela gigantesca quantidade de voos bem-sucedidos, resultado de esforço multidisciplinar e inegociável busca pela perfeição por mais de um século, faz com que cada vez mais este modal de transporte seja utilizado pelas pessoas, ainda que o medo de voar seja uma das fobias latentes mais comuns a atormentar o ser humano moderno. Os benefícios latentes que, socialmente e academicamente, ainda poderão ser extraídos dos estudos sociais aplicados parecem justificar uma afinidade intrínseca com os compromissos da postura descrita (Lima, 2011:207).

Seguindo essa defesa ao multiparadigmatismo, o presente artigo está estruturado de forma a discutir paradigmas, metodologias qualitativa e quantitativa de pesquisa (item 2); a triangulação como validação convergente ou como conversação entre paradigmas (item 3); a apresentar os procedimentos metodológicos adotados (item 4); demonstrar as análises realizadas (item 5); fazer algumas discussões (item 6) e apresentar as considerações finais da pesquisa (item 7).

\section{Sobre paradigmas, metodologias quantitativa e qualitativa de pesquisa}

O conceito de paradigma é tratado de diversas formas, assumindo significados diversos (Bastos Filho, 2000). Há abordagens como a de Kuhn (1962), que criou o conceito em si (Serva, 1992; Bastos Filho, 2000), e de Burrell e Morgan (1979), cuja relevância se tornou significativa para os estudos organizacionais. Kuhn (2005:13) define paradigma como "as realizações científicas universalmente reconhecidas que, durante algum tempo, fornecem problemas e soluções modelares para uma comunidade de praticantes de uma ciência”. O paradigma, para Kuhn (1962), é precedido por uma visão de mundo, por valores e crenças que são compartilhados por uma comunidade científica. Dessa forma, ele se torna um ele- 
mento fundamental que orienta a prática científica, podendo ser considerado uma mentalidade científica (Szczepanik, 2008).

Dentro do contexto dos estudos organizacionais, por sua vez, a discussão sobre paradigma ganha evidência quando Burrell e Morgan (1979) formulam uma classificação entre quatro paradigmas na pesquisa organizacional, que pode ser observada na Figura 1.

Figura 1

Paradigmas na teoria organizacional

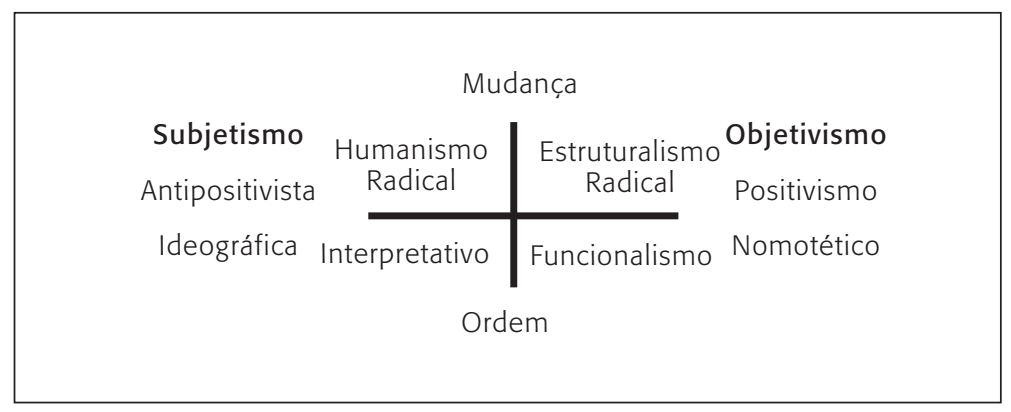

Fonte: adaptado de Burrell e Morgan (1979).

Para os autores, os paradigmas são como lentes por meio das quais o pesquisador vê o mundo e, por conseguinte, conduz suas investigações. Nesse sentido, sua escolha metodológica normalmente envolve um respeito à ontologia e à epistemologia relativas ao paradigma com o qual se identifica (Feitosa e Popadiuk, 2009). Na visão de Burrell e Morgan (1979:24, tradução nossa), "estar localizado em um paradigma particular é ver o mundo de uma forma particular. Os paradigmas dizem respeito a visões do mundo social baseadas em diferentes pressupostos metateóricos relativos à natureza da ciência e da sociedade".

Como a noção de paradigma envolve diferentes concepções ontológicas e epistemológicas, torna-se necessário discutir do que tratam a ontologia e a epistemologia. Ontologia reflete a crença que se tem da natureza do mundo e daquilo que se pode saber sobre o mesmo. Epistemologia, por sua vez, reflete a crença que se tem da natureza do conhecimento e como ele pode ser adquirido (como é possível conhecer o mundo), que compreende, basicamente, duas posições consideradas distintas: o positivismo e o interpretativismo (Snape e Spencer, 2003). O positivismo

[...] sustenta que os métodos das ciências naturais sejam apropriados para a investigação social porque o comportamento humano é governado por regularidades como leis; e que seja possível conduzir uma pesquisa social independente, objetiva e livre de valores. A visão oposta, conhecida como interpretativismo, defende que os métodos das ciências naturais não são apropriados para a investigação social porque o mundo social não é governado por regularidades que funcionam como propriedades na forma de leis. [...] um pesquisador social tem que explorar e entender o 
mundo social por meio da perspectiva dos participantes e de sua própria perspectiva [...] (Snape; Spencer, 2003:23).

Por sua vez, a postura epistemológica se reflete nas escolhas metodológicas, que podem ser agrupadas em ideográficas (antipositivistas) e nomotéticas (positivistas). Considerando o positivismo e o interpretativismo como duas diferentes posições epistemológicas, os mesmos podem ser associados, respectivamente, à pesquisa de natureza quantitativa e à pesquisa de natureza qualitativa. Quanto à pesquisa qualitativa, pode-se dizer que o termo é utilizado para cobrir uma ampla gama de abordagens e métodos provenientes de diferentes disciplinas de pesquisa. Contudo, pode-se capturar a essência do que ela é por meio da descrição de características que lhe são chaves (Snape e Spencer, 2003). Nesse sentido,

A pesquisa qualitativa é uma atividade situada que localiza o observador no mundo. Consiste de um conjunto de práticas interpretativas e materiais que tornam o mundo visível. Essas práticas [...] trazem o mundo para dentro de uma série de representações [...]. Neste nível, a pesquisa qualitativa envolve uma abordagem interpretativa e naturalística para o mundo. Isso significa que os condutores de pesquisa qualitativa estudam as coisas em suas características naturais, tentando dar um sentido ou interpretar um fenômeno nos termos dos significados que as pessoas atribuem a ele (Denzin e Lincoln, 2000:3, apud Snape e Spencer, 2003:2-3, tradução nossa).

A pesquisa qualitativa não conduz medições nem quantificação de resultados, pois busca a obtenção de dados descritivos sobre os fenômenos estudados, especialmente sobre pessoas, lugares e processos interativos (Godoy, 1995). O desenvolvimento da pesquisa qualitativa nas ciências sociais e humanas se deu como uma forma de superar as limitações percebidas dos métodos que prevaleciam para o estudo do comportamento humano, que compreendiam a pesquisa quantitativa. Dessa forma, as tradições qualitativas e quantitativas foram desenvolvidas de forma contrastante (Downey e Ireland, 1979; Godoy, 1995; Snape e Spencer, 2003).

O predomínio da pesquisa quantitativa e do positivismo na administração foi significativo, assim como ocorreu na pesquisa social como um todo. Vergara e Caldas (2005) afirmam que, devido à predominância do funcionalismo como epistemologia da pesquisa e educação dos docentes, "produziu-se no Brasil uma geração de pesquisadores e educadores em estudos organizacionais que tiveram acesso restrito a outros paradigmas de análise organizacional, assim como menos incentivo e receptividade para aprofundar-se em descobri-los" (Vergara e Caldas, 2005:66). Os principais pressupostos das abordagens positivistas são que

[...] os métodos das ciências naturais são apropriados para o estudo do fenômeno social; somente aqueles fenômenos que são observáveis podem ser considerados conhecimento; o conhecimento é desenvolvido indutivamente por meio da acumulação de fatos verificados; as hipóteses são derivadas dedutivamente das teorias científicas a serem testadas empiricamente (o método científico) [...] (Snape e Spencer, 2003:6). 
A pesquisa quantitativa é a que mais se aproxima dos citados pressupostos, pois os "pesquisadores quantitativos puristas articulam pressupostos que são consistentes com o que é comumente chamado de filosofia positivista" (Johnson e Onwuegbuzie, 2004:14, tradução nossa). Além disso, as tradições empiristas e positivistas, mais relacionadas à pesquisa quantitativa, trazem a noção de neutralidade do pesquisador, o que se choca com as correntes interpretativas, que desconsideram tal neutralidade. Nessa dualidade, os "pesquisadores qualitativos puristas rejeitam o que eles chamam de positivismo. Eles argumentam a favor da superioridade do construtivismo, do idealismo, do relativismo, do humanismo, da hermenêutica" (Johnson e Onwuegbuzie, 2004:14, tradução nossa).

Dessa forma, há aqueles pesquisadores que acreditam que seus paradigmas sejam os ideais para a pesquisa e que, de forma implícita ou explícita, defendem a tese da incomensurabilidade paradigmática, a qual compreende a ideia de que "os paradigmas de pesquisa qualitativa e quantitativa, incluindo seus métodos associados, não podem e não devem ser combinados" (Johnson e Onwuegbuzie, 2004:14, tradução nossa). Assim, há um intenso debate na pesquisa social sobre até que ponto as abordagens qualitativas e quantitativas deveriam ou poderiam ser combinadas. Enquanto alguns autores defendem que ambas sejam tão diferentes em suas origens filosóficas que não possam ser combinadas, outros, apesar de admitirem suas diferentes bases ontológicas e epistemológicas, reconhecem o valor de se utilizar as duas abordagens de forma conjunta (Ritchie, 2003), noção esta que corrobora a postura dos pesquisadores do presente estudo.

O conceito de incomensurabilidade paradigmática foi introduzido por Kuhn (1962) como representando a incompatibilidade de duas teorias científicas que se sucedem relativamente a pressupostos, métodos e ontologia. No campo dos estudos organizacionais, Burrell e Morgan (1979) também defenderam a tese da incomensurabilidade em um posicionamento que lhes renderam significativas críticas. Burrell (2007:448) afirma que "o problema da incompatibilidade de paradigmas permanece justo no centro dos problemas dos paradigmas organizacionais". Sua significância é importante, tanto que Tadajewski (2009) chega a questionar se este é um debate que não morrerá.

Falando em debate, Burrell (2007) chama a atenção para o caráter político da defesa pela incomensurabilidade, afirmando que, para os guerreiros do paradigma (os defensores da incomensurabilidade), o isolacionismo é uma forma de garantia da própria sobrevivência de suas abordagens e de seu ponto de vista ideológico. Ou seja, é também uma forma de protecionismo paradigmático, já que a "crença na incompatibilidade então tem sua origem na política, tanto quanto na epistemologia" (Burrell, 2007:449).

Kuhn (2000), em outro momento, associa a incomensurabilidade a uma dimensão da linguagem, em que os paradigmas representam modelos de linguagem que são de difícil compreensão para grupos de outros paradigmas, o que poderia levar a um não entendimento alheio. Dessa forma, pode-se interpretar que

[...] a noção de incomensurabilidade não deve ser considerada de forma radical e sim, mais como uma dificuldade de comunicação do que uma impossibilidade. Pois o próprio Kuhn (2000) revela 
a possibilidade do diálogo entre duas teorias distintas, com léxicos diferentes, por meio do aprendizado do léxico da outra comunidade científica (Teixeira e Nascimento, 2010:4).

Além disso, há uma "largamente difundida retração da incompatibilidade [que] precisa ser contada" (Burrell, 2007:450), retração essa que se associa à noção de multiparadigmatismo, que "refere-se à crença na possibilidade de conversa entre os paradigmas e da realização de pesquisas científicas que se baseiem em mais de um paradigma" (Teixeira e Nascimento, 2010:8). Para Hoyningen-Huene (1993), a noção kuhniana de incomensurabilidade não pode implicar a crença de descontinuidade radical entre teorias que se sucedem, pois realizações concretas dos paradigmas antecessores tendem a ser preservadas, sendo Czarniawska (1998) também outra autora que demonstra um posicionamento contrário à incomensurabilidade.

Contudo, continua significativa a defesa de sua tese, o que acreditamos ser uma não muito benéfica resistência, já que, como questiona Hassard (1993:75, apud Burrell, 2007:450), "se cientistas não podem debater, como o progresso pode ser assinalado?". Jackson e Carter (1991), por exemplo, são autores que continuam a defender rigorosamente a incomensurabilidade.

Scherer e Steinmann (1999:523, tradução nossa) defendem que "os adeptos do multiparadigmatismo tendem a subestimar o problema da incomensurabilidade". Para os autores, eles negligenciam o fato de que a incomensurabilidade significa que "a coexistência de diferentes posições não é possível", acusando-os de confundir "[...] um mero pluralismo de diferentes perspectivas, em que essa coexistência é algumas vezes justificável, com uma situação de sério conflito, em que tal coexistência não é possível". Acreditamos que a opinião de Scherer e Steinmann (1999) possa ser analisada de acordo com um aspecto que é central neste artigo: o de que há pesquisadores que combinam perspectivas diferentes sem, de fato, implicar a adoção de diferentes visões paradigmáticas. Ou seja, o pluralismo ou a mera adoção de diferentes perspectivas pode não atingir o âmbito paradigmático. Tal associação pode ainda ser reforçada quando Scherer e Steinmann (1999:523) afirmam que

[...] os adeptos do multiparadigmatismo geralmente se concentram na combinação dentro da dimensão metodológica. Ou seja, eles tentam demonstrar como paradigmas objetivistas e subjetivistas podem ser reconciliados ou pelo menos combinados (por exemplo, Gioia, Pitre, 1990; Lee, 1991; Spender, 1992), mas negligenciam uma reconciliação de diferentes posições ou até mesmo defendem explicitamente que tal reconciliação não seria possível a princípio [...].

No entanto, os próprios autores demonstram uma possível solução para o problema da incomensurabilidade, que seria o método da argumentação que, segundo eles, visaria a um consenso. Scherer e Steinmann (1999) utilizam o conceito de argumentação de Lueken (1991:246, apud Scherer e Steinmann, 1999:526, grifo nosso): "uma ação simbólica desenvolvida para superar uma controvérsia e chegar a um consenso", afirmando que tal conceito 
contém "o potencial para uma solução racional do problema da incomensurabilidade" (Scherer e Steinmann, 1999:526, grifo nosso). Nesse sentido, defendem que

[...] o problema da incomensurabilidaade não possui uma solução teórica, mas que há a possibilidade prática de uma resolução quando aqueles que estão diretamente envolvidos com um conflito de posições incomensuráveis trabalham na transição de seus sistemas de orientação até que um entendimento mútuo ou um eventual acordo pode ser obtido (Scherer e Steinmann, 1999:536-537, grifo do autor).

O que nos preocupa no posicionamento de Scherer e Steinmann (1999) é a busca por uma "solução racional" para o "problema" da incomensurabilidade, e também seu entendimento de que tal solução seria a chegada a um "consenso" entre as diferentes posições, o que demonstra uma visão, diríamos, com conotações significativamente positivistas. A solução para um problema nos lembra uma linguagem matemática, e a busca por um consenso, a buscada ordem positivista. Será que o consenso é o desejado nas combinações multiparadigmáticas? Acreditamos que não necessariamente. Além disso, a busca de soluções para problemas pode refletir também um desejo de se chegar a respostas finais e tidas como verdadeiras para conflitos de ordem paradigmática, o que não defendemos como sendo necessário e nem mesmo benéfico diante da complexidade dos fenômenos sociais.

Considerando a vinculação dos aspectos epistemológicos (característicos dos paradigmas) com as escolhas metodológicas, havendo defensores contrários à noção de incomensurabilidade, há também avanços relativos à consideração de que a pesquisa qualitativa e a quantitativa não sejam mutuamente exclusivas (Jick, 1979; Downey e Ireland, 1979; Pope e Mays, 1995; Neves, 1996). Snape e Spencer (2003), por exemplo, chamam a atenção para o fato de que existem diferenças entre ambas, mas que essa distinção não é absolutamente clara, pois algumas pesquisas qualitativas, por exemplo, podem também utilizar modelos próximos das ciências naturais, enquanto nem todos os estudos quantitativos baseiam-se em testes de hipóteses, produzindo unicamente estatísticas descritivas e indutivas.

Assim, mesmo sendo metodologias oriundas de paradigmas contrastantes, estes não são necessariamente opostos. Pelo contrário, podem representar visões complementares de uma mesma realidade. Além disso, defende-se que a pesquisa que combina métodos possa resultar em uma pesquisa superior, se comparada à pesquisa que utiliza apenas um método (Johnson e Onwuegbuzie, 2004; Souza e Zioni, 2003; Jick, 1979).

Vale ressaltar que o objetivo de se combinar métodos não é o de substituir as abordagens estritamente qualitativas ou quantitativas, mas o de representar uma alternativa possível de se aumentarem as forças e reduzirem as fraquezas de estudos que utilizam apenas uma perspectiva (Johnson e Onwuegbuzie, 2004). Além disso, há autores que são contrários à própria polarização entre abordagens subjetivas e objetivas nas ciências sociais, que é inerente à mentalidade dualística característica da noção de paradigma, tal como Willmott (1993). E é nesse contexto que se insere a discussão sobre triangulação metodológica. 


\section{Combinando os métodos: triangulação como mera validação convergente ou conversação entre paradigmas}

Combinar métodos qualitativos e quantitativos pode representar uma simples fusão dos resultados oriundos em cada uma das abordagens ou ir além, conjugando diferentes tipos de pensamento sobre um tema (Ritchie, 2003). Dessa forma, conjugam-se os benefícios de ambas as abordagens para enriquecer uma pesquisa, em um processo no qual se pode obter "alguma forma de medida, mas também uma melhor compreensão da natureza ou das origens de um problema" (Ritchie, 2003:38).

Nesse sentido, cabe discutir a noção envolvida com o conceito de triangulação metodológica. Aqui adotada no sentido de combinação de métodos qualitativos e quantitativos, a triangulação pode ser definida como a utilização de múltiplos métodos para a investigação de um mesmo fenômeno (Jick, 1979; Mathison, 1988; Morse, 1991; Blaikie, 1991; Duffy, 2007) em pesquisa, envolvendo a combinação de pelo menos dois métodos, sendo um quantitativo e outro qualitativo (Morse, 1991).

Como na literatura faz-se referência também a outras denominações de triangulação, entre elas a de validação convergente (Jick, 1979), torna-se necessário discutir a extensão do conceito relativamente à mera combinação de métodos no intuito de validar os resultados da pesquisa ou, de fato, a uma combinação de métodos que implique uma conversação relativa às diferentes bases paradigmáticas de cada um dos métodos. Nesse sentido, Ottoboni (2009:1, grifos da autora) destaca que

O próprio nome triangulação de paradigmas tem suscitado muitas discussões. Bazeley (2002) afirma que o termo triangulação, desde sua popularização na década de 80 , tem sido erroneamente utilizado quanto ao propósito e ao projeto. Inicialmente, foi concebido como a condução de estudos utilizando diferentes métodos para alcançar o mesmo propósito, isto é, como técnica de validação. Já, mais recentemente, vem sendo utilizado como sinônimo de métodos mistos de pesquisa [...].

A denominação significativamente encontrada na literatura atualmente é a de mixed methods research. Vale ressaltar que, quando se usa essa denominação, corre-se o risco de considerá-la em uma dimensão estritamente metodológica, como ressaltado por Tashakkori e colaboradores (1998), apud Ottoboni (2009), o que pode ser equivocado, já que "a distinção quantitativo qualitativo deve ser aplicada aos vários níveis: projeto e análise dos dados, interpretação dos resultados e, também, no do paradigma epistemológico adotado" (Ottoboni, 2009:2). Tal concepção envolve a noção de triangulação defendida no presente estudo, que seria aquela que permitiria uma conversação entre diferentes perspectivas e não necessariamente (ou meramente) uma busca por maior precisão, validade e confiabilidade da pesquisa por meio da validação. Contudo, é importante destacar a relevância desta noção de triangulação como mera validação na literatura, que pode ser exemplificada pela afirmação de Ritchie (2003:43, tradução nossa, grifos do autor) de que o termo foi inicialmente utilizado 
[...] em conexão com a validação de medidas derivada de dados quantitativos estruturados (Campbell e Fiske, 1959). A triangulação envolve o uso de diferentes métodos e fontes para checar a integridade ou estender as inferências oriundas dos dados. Tem sido amplamente adotada e desenvolvida como um conceito dos pesquisadores qualitativos como um modo de investigar a convergência tanto dos dados quanto das conclusões que deles derivam (Denzin, 1994). É também frequentemente citada como uma das principais formas de validar as evidências da pesquisa qualitativa.

Neste trecho, observa-se claramente como o conceito foi originalmente utilizado como simples forma de oferecer aos pesquisadores qualitativos um modo de verificar seus resultados (Ritchie, 2003), o que revela, na verdade, uma desconfiança relativa à validade da pesquisa qualitativa. E que, portanto, só faz sentido dentro de uma concepção positivista da ciência, como se observa na afirmação de que "a triangulação assume que o uso de diferentes fontes de informação ajudará tanto a confirmar quanto a melhorar a claridade, ou a precisão, do resultado de uma pesquisa" (Lewis e Ritchie, 2003:275).

A desconfiança em relação à pesquisa qualitativa também é abordada por Mattos (2011), que faz uma crítica a ressalvas do tipo: "os resultados desta pesquisa (qualitativa) não podem ser generalizados". Mattos (2011) afirma que os autores de pesquisa qualitativa, ao repetirem como bordão essa explicação, acabam por implicitamente reconhecer o estudo como de "segunda linha". Para o autor, "trata-se da afirmação implícita da hegemonia e superioridade de um processo lógico em ciência, a generalização indutiva” (Mattos, 2011:451). "O que significa, então, dizer "Os resultados desta pesquisa qualitativa não podem ser generalizados"? - Que o autor, sentindo-se na obrigação de explicar que está fora do paradigma empírico das ciências naturais, com isso envolve-se em um juízo de valor" (Mattos, 2011:463).

Para caminharmos na contramão da perspectiva de triangulação que atende a essa desconfiança em relação à pesquisa qualitativa, ou que a trate simplesmente como uma validação convergente, sugerimos a adoção do termo triangulação ou métodos mistos de pesquisa dentro de uma concepção que enfatiza que as pesquisas qualitativas e quantitativas representam diferentes modos de se considerar a realidade e o conhecimento científico. Dessa forma, a riqueza de sua combinação estaria no fato de que podem propiciar uma leitura diferente do mesmo problema de pesquisa e de se considerar que, não necessariamente, "as evidências geradas pelas duas abordagens irão se replicar mutuamente" (Ritchie, 2003:43) (ela pode propiciar, por exemplo, uma validação divergente). Ou seja, defende-se que a segurança que a triangulação fornece é uma visão mais completa do fenômeno, não necessariamente uma mais correta (Ritchie, 2003:44).

Nesse sentido, defende-se que a triangulação metodológica possa ser um meio de se realizar estudos multiparadigmáticos, os quais podem, de acordo com Lewis e Grimes (2005), contribuir para uma melhor apreensão das complexidades organizacionais. Assim, há autores que defendem que as diferenças entre os paradigmas tradicionais de pesquisa sejam de fato significativas, mas que, sendo eles mesmos construções sociais e históricas, não são invioláveis ou sacrossantos, e que tratar dialogicamente as diferenças entre os mesmos possa gerar 
novos insights e novas compreensões para os fenômenos, tais como Greene e Caracelli (1997) e Maxwell e Loomis (2003).

Importante ressaltar que, em meio a essa discussão, há autores que acreditam que a reconciliação das históricas e filosóficas incomensurabilidades paradigmáticas possa ocorrer somente por intermédio da emergência de novos paradigmas, tais como Johnson e Onwuegbuzie (2004) e Teddlie e Tashakkori (2003). E um dos paradigmas apontados como passíveis de levar a essa reconciliação é o pragmatismo (Greene, 2008). Belloquim e Lacombe (2003), por exemplo, acreditam que noções do pragmatismo clássico estejam presentes nos estudos em administração, embora não de forma explícita. Para os autores, o pragmatismo está, de forma implícita, no funcionalismo descrito por Burrell e Morgan (1979) em sua classificação paradigmática para os estudos organizacionais. Morgan (2007) também defende que a abordagem pragmática seja um novo paradigma que serve como base para trabalhos que combinam métodos qualitativos e quantitativos.

Uma das características do pragmatismo é sua rejeição a dualismos tradicionais, tais como racionalismo versus empirismo, realismo versus antirrealismo, subjetivismo e objetivismo (Johnson e Onwuegbuzie, 2004). A abordagem pragmática se caracteriza pela abdução, que "se move entre indução e dedução, para frente e para trás, convertendo observações em teorias e avaliando tais teorias através da ação" (Ottoboni, 2009:13); e pela intersubjetividade, que "representa a ênfase no processo de comunicação e significado compartilhado que são centrais na abordagem pragmática", tendo ainda a noção de que "a dicotomia entre subjetivo e objetivo é um resumo artificial do relacionamento entre pesquisador e processo de pesquisa" (Ottoboni, 2009:13), capturando essa dualidade.

Porém, não desconsiderando a importância dessa forma específica de analisar a combinação de métodos, considera-se que recorrer à existência de um terceiro paradigma metodológico como representando esta combinação é uma forma de desviar a discussão acerca das divergências entre os paradigmas já existentes, dando a impressão de que a combinação é sim aceita, porém em um novo paradigma, em um espaço diferente daqueles ocupados pelos paradigmas conhecidos. Dessa forma, acreditamos que tal visão possa polarizar ainda mais o debate ao criar um espaço específico que possa garantir a legitimação da pesquisa multimétodos, distante das tensões entre possíveis zonas de conversação entre os paradigmas.

Definido então o referencial teórico da pesquisa e a postura adotada pelos autores, segue-se a descrição dos procedimentos metodológicos adotados.

\section{Procedimentos metodológicos}

Para responder à principal questão da presente pesquisa - a triangulação como método tem sido utilizada nas pesquisas em administração de uma perspectiva multiparadigmática, gerando conversações entre paradigmas? Ou tem sido utilizada simplesmente no intuito de se realizar uma validação "convergente" entre os métodos na pesquisa? - , a metodologia adotada foi qualitativa, pois para analisar o modo como os resultados obtidos pelas pesquisas 
qualitativas e quantitativas foram tratados de forma conjunta em um mesmo estudo, julgouse necessária uma análise mais específica em cada artigo, por intermédio principalmente da análise do discurso empregado pelos autores ao demonstrar os resultados e as conclusões de suas pesquisas. Em termos quantitativos, foi realizada apenas uma distribuição percentual dos artigos relativamente ao modo como empregaram a triangulação.

Dessa forma, a coleta de dados se deu por meio de pesquisa documental dos artigos publicados nos anais do EnAnpad de 2007 a 2009 que utilizaram a triangulação (174 artigos). O método de análise empregado, por sua vez, foi a análise de conteúdo (qualitativa), que é um conjunto de técnicas de análise das comunicações que visa obter indicadores que permitem a inferência de conhecimentos relativos às condições de produção/recepção das mensagens (Bardin, 2004), permitindo revelar os sentidos do conteúdo (Laville e Dionne, 1999), método este também empregado por Bryman (2007) em estudo que analisou justamente artigos que utilizaram a abordagem multimétodos.

\section{Como a triangulação tem sido utilizada nas pesquisas em administração}

Para analisar de que forma a triangulação tem sido utilizada nas pesquisas em administração, observaram-se a forma de apresentação dos resultados das pesquisas, a postura paradigmática prevalecente nos estudos e o sentido em que a triangulação foi adotada.

\subsection{Forma de apresentação dos resultados das pesquisas}

Em primeiro lugar, analisou-se de que forma os resultados das fases qualitativa e quantitativa das pesquisas foram apresentados e explorados nos artigos que fizeram uso da triangulação. Como foi dito na introdução, a incidência de artigos que fizeram o uso foi de apenas 6\%, como se observa na tabela 1 .

Tabela 1

Incidência de artigos que utilizaram a triangulação metodológica nos anais do EnAnpad de 2007 a 2009

\begin{tabular}{|lccc|}
\hline \multicolumn{1}{|c}{ TOTAL - 2007 a 2009 } & Artigos publicados & Artigos - Triangulação & $\begin{array}{c}\text { Incidência de } \\
\text { Triangulação }\end{array}$ \\
\hline GPR - Gestão de Pessoas e Relações de Trabalho & 263 & 26 & $10 \%$ \\
MKT - Marketing & 305 & 29 & $10 \%$ \\
APS - Administração Pública e Gestão Social & 426 & 33 & $8 \%$ \\
ADI - Administração da Informação & 181 & 12 & $7 \%$ \\
\hline
\end{tabular}




\begin{tabular}{|llll|}
\hline \multicolumn{1}{|c}{ TOTAL - 2007 a 2009 } & Artigos publicados & Artigos - Triangulação & $\begin{array}{c}\text { Incidência de } \\
\text { Triangulação }\end{array}$ \\
\hline $\begin{array}{l}\text { EPQ - Ensino e Pesquisa em Administração e Contabi- } \\
\text { lidade }\end{array}$ & 268 & 16 & $6 \%$ \\
EOR - Estudos Organizacionais & 345 & 18 & $5 \%$ \\
ESO - Estratégia em Organizações & 344 & 17 & $5 \%$ \\
CON - Contabilidade & 230 & 11 & $5 \%$ \\
GOL - Gestão de Operações e Logística & 132 & 6 & $5 \%$ \\
GCT - Gestão de Ciência, Tecnologia e Inovação & 181 & 6 & $3 \%$ \\
FIN - Finanças & 178 & 0 & $0 \%$ \\
& 2853 & 174 & $6 \%$ \\
\hline
\end{tabular}

Fonte: Teixeira, Antonialli e Nascimento (2010).

Assim, discutir as formas de relatos das pesquisas que combinam métodos se torna algo relevante, já que é ainda uma discussão incipiente, como reforça Bryman (2007). Além disso, não há um desenvolvimento adequado em relação à combinação de métodos em si, pois as discussões ainda giram muito em torno da possibilidade ou não de se combinarem as metodologias quantitativas e qualitativas de pesquisa.

As análises qualitativas dos artigos permitiram a observação do seguinte panorama relativo à apresentação dos resultados:

Tabela 2

Forma em que os resultados foram apresentados

\begin{tabular}{|c|c|c|c|c|c|}
\hline \multicolumn{6}{|c|}{ Forma que os resultados são apresentados } \\
\hline $\begin{array}{c}\text { Divisão temática } \\
\text { do evento }\end{array}$ & $\begin{array}{c}\text { Artigos } \\
\text { triangulação }\end{array}$ & $\begin{array}{c}\text { Percentual } \\
\text { que declara de } \\
\text { forma explícita } \\
\text { que o estudo é } \\
\text { quantitativo e } \\
\text { qualitativo }\end{array}$ & $\begin{array}{c}\text { Percentual } \\
\text { que descreve } \\
\text { diretamente a } \\
\text { análise dos dados } \\
\text { quantitativos }\end{array}$ & $\begin{array}{c}\text { Percentual } \\
\text { que descreve } \\
\text { diretamente a } \\
\text { análise dos dados } \\
\text { qualitativos }\end{array}$ & $\begin{array}{c}\begin{array}{c}\text { Percentual } \\
\text { que integra }\end{array} \\
\text { os resultados } \\
\frac{\text { qualitativos e }}{\text { quantitativos nas }} \\
\frac{\text { análises }}{\underline{\text { quás }}}\end{array}$ \\
\hline GPR & 26 & $88 \%$ & $100 \%$ & $54 \%$ & $45 \%$ \\
\hline MKT & 29 & $86 \%$ & $100 \%$ & $45 \%$ & $11 \%$ \\
\hline APS & 33 & $100 \%$ & $100 \%$ & $48 \%$ & $24 \%$ \\
\hline ADI & 12 & $50 \%$ & $100 \%$ & $58 \%$ & $33 \%$ \\
\hline$E P Q$ & 16 & $68 \%$ & $88 \%$ & $83 \%$ & $66 \%$ \\
\hline EOR & 18 & $100 \%$ & $100 \%$ & $72 \%$ & $39 \%$ \\
\hline ESO & 17 & $100 \%$ & $100 \%$ & $60 \%$ & $0 \%$ \\
\hline
\end{tabular}




\begin{tabular}{|c|c|c|c|c|c|}
\hline \multicolumn{6}{|c|}{ Forma que os resultados são apresentados } \\
\hline $\begin{array}{c}\text { Divisão temática } \\
\text { do evento }\end{array}$ & $\begin{array}{c}\text { Artigos } \\
\text { triangulação }\end{array}$ & $\begin{array}{c}\text { Percentual } \\
\text { que declara de } \\
\text { forma explícita } \\
\text { que o estudo é } \\
\text { quantitativo e } \\
\text { qualitativo }\end{array}$ & $\begin{array}{c}\text { Percentual } \\
\text { que descreve } \\
\text { diretamente a } \\
\text { análise dos dados } \\
\text { quantitativos }\end{array}$ & $\begin{array}{c}\text { Percentual } \\
\text { que descreve } \\
\text { diretamente a } \\
\text { análise dos dados } \\
\text { qualitativos }\end{array}$ & $\begin{array}{c}\begin{array}{c}\text { Percentual } \\
\text { que integra }\end{array} \\
\text { os resultados } \\
\begin{array}{c}\text { qualitativos e } \\
\text { quantitativos nas }\end{array} \\
\underline{\text { análises }}\end{array}$ \\
\hline CONT & 11 & $100 \%$ & $100 \%$ & $25 \%$ & $0 \%$ \\
\hline GOL & 6 & $100 \%$ & $100 \%$ & $50 \%$ & $0 \%$ \\
\hline GCT & 6 & $100 \%$ & $100 \%$ & $50 \%$ & $33 \%$ \\
\hline TOTAL & 174 & $89 \%$ & $99 \%$ & $54 \%$ & $27 \%$ \\
\hline
\end{tabular}

Como se observa, os autores admitem claramente na maior parte dos estudos que a pesquisa é quantitativa e qualitativa, o que representa $89 \%$ do total. Mas no momento de demonstrar as análises dos dados, observam-se grandes discrepâncias relativas à demonstração da combinação que foi realizada. Em vários casos, é demonstrado apenas o relato de uma das etapas, qualitativa ou quantitativa, o que não demonstra satisfatoriamente ao leitor a forma com que os resultados foram trabalhados, enquanto oriundos de estudos multimétodos. Além disso, a ênfase que é dada a uma das etapas permite demonstrar indícios de uma efetiva conversação paradigmática ou não nos estudos. Mas, por ora, neste item, as análises limitam-se ao aspecto metodológico, sendo o aspecto paradigmático explorado a seguir, já que a simples análise de como os dados foram trabalhados não permite, necessariamente, verificar a combinação ou não de visões de uma realidade.

Os dados descritos na tabela 2 permitem a observação de que $99 \%$ dos estudos demonstram de forma direta a análise dos dados quantitativos, enquanto apenas 54\% demonstram diretamente a análise dos dados qualitativos, o que denota uma preocupação maior com o relato dos métodos de análise quantitativos. Embora combinem métodos, não há uma significativa preocupação em demonstrar de que forma os dados e métodos qualitativos foram explorados, o que implica, em decorrência, um menor nível de integração dos resultados. Relativamente ao mesmo, observou-se que apenas $27 \%$ dos estudos trouxeram de forma integrada os resultados quantitativos e qualitativos. Nesse sentido, os estudos da divisão de EPQ - Ensino e Pesquisa em Administração e Contabilidade - foram os que apresentaram maior equilíbrio em relação tanto à demonstração dos resultados qualitativos e quantitativos, quanto à integração desses resultados. Em contrapartida, os estudos da divisão de CON — Contabilidade - foram os que menos demonstraram as análises qualitativas, além de não integrarem os resultados.

Corroborando o que se observa nesses estudos multimétodos publicados nos anais do EnAnpad, congresso brasileiro, Bryman (2007) observou, em uma análise de estudos ingleses que combinaram métodos, que "pesquisadores multimétodos nem sempre trazem os resultados conjuntamente e que os componentes quantitativos e qualitativos são tratados como domínios separados" (Bryman, 2007:9, tradução nossa). A falta de integração pode ser con- 
siderada uma limitação, já que "trazer os resultados quantitativos e qualitativos de forma integrada tem o potencial de oferecer insights que poderiam não ser obtidos de outra forma" (Bryman, 2007:9, tradução nossa). Bryman (2007) defende que mais atenção deve ser dada à escrita e aos relatórios de pesquisas que combinam métodos. No mesmo sentido, Creswell e Tashakkori (2007:108, tradução nossa) enfatizam que “[...] a pesquisa multimétodos é simplesmente mais do que o relatório de duas pesquisas quantitativa e qualitativa [...]. A expectativa é que ao final, as conclusões [...] sejam integradas para oferecer uma melhor compreensão do fenômeno estudado", o que não se observa de forma significativa nos estudos analisados.

Trazer os resultados de forma integrada também permite que se demonstre de que forma a combinação contribui para o conhecimento dos fenômenos analisados. Há exemplos de artigos que analisam de forma conjunta, por exemplo, resultados obtidos com questionários estruturados e com entrevistas em profundidade, o que contribui para uma visão mais ampla do fenômeno analisado. Contudo, em contrapartida, o modo como a maioria dos artigos traz a apresentação dos resultados não demonstra muita ênfase aos dados qualitativos, pois há uma grande preocupação, por exemplo, com afirmações de natureza percentual e com a demonstração dos dados estatísticos e quantitativos. Em grande parte dos trabalhos, as análises se resumem, ao final, a dados quantitativos. Em um artigo da divisão de CON, por exemplo, o autor descreve que:

Quanto à forma de abordagem do problema esta pesquisa classifica-se como quantitativa e qualitativa. Quantitativa por efetuar-se a mensuração específica das informações coletadas, transformando-as em indicadores econômicos e financeiros. Qualitativa em função da análise do significado da qualidade de tais indicadores, traduzindo-os em referenciais qualitativos a respeito do desempenho da empresa analisada (Artigo CON).

Porém, ao demonstrar os resultados, há maior ênfase nos dados quantitativos, sendo os qualitativos inclusive transformados em instrumentais quantitativos. Em um artigo da divisão de ESO, por exemplo, os resultados não são apresentados de forma integrada e apenas um quadro e um parágrafo são dedicados à demonstração dos resultados qualitativos, enquanto para a demonstração da análise quantitativa são utilizadas aproximadamente quatro páginas. Em alguns artigos, embora haja combinação, há descrição de dados quantitativos durante todo o tempo. O que se destaca, principalmente, é a análise quantitativa como fim, sendo a qualitativa considerada um meio, o que se observa especialmente na transformação significativa das análises qualitativas em percentuais.

Além disso, há significativa utilização da pesquisa qualitativa apenas em um sentido exploratório, principalmente para a construção dos instrumentos quantitativos da pesquisa, o que denota uma possível consideração de que a pesquisa qualitativa, por si só, possa ser "incompleta".

Corroborando os resultados obtidos, Bansal e Corley (2011:234), em um editorial sobre pesquisa qualitativa na Academy of Management Journal, afirmam que editores da revista ob- 
servaram que artigos nela publicados que utilizaram métodos mistos de pesquisa tinham uma forma e função que tipicamente seguiam uma estrutura mais quantitativa.

[...] parece que a maioria desses estudos usam os dados qualitativos para servirem ao estudo quantitativo, tanto validando os construtos ou simplesmente oferecendo explicações para resultados quantitativos. Seria interessante ver abordagens mais inovativas para os métodos mistos, como o uso dos dados qualitativos para percepções mais profundas dos dados quantitativos (Bansal e Corley, 2011:236).

Não se defende aqui a superioridade do qualitativo ou do quantitativo como forma mais adequada de se realizar uma pesquisa, apenas se fazem observações relativas ao modo como os estudos têm combinado os métodos, e que visões de realidade predominam.

A integração dos resultados, metodologicamente, pode ser considerada um passo importante para que, em um nível mais avançado, haja, de fato, conversações epistemológicas nos estudos, já que a metodologia guarda pressupostos epistemológicos e ontológicos de pesquisa. Como já esclarecido, defende-se neste artigo o não tratamento do método enquanto algo fragmentado de suas bases paradigmáticas. Em estudos que combinam métodos, seja de forma paralela ou sequencial, a exploração de interfaces entre as diferentes visões se torna importante, como se observa na descrição de Ottoboni (2009:11-12, grifos da autora), quando destaca o que fazem os estudos multiparadigmáticos:

Nos estudos paralelos, pesquisadores preservam os conflitos teóricos quando escrevem vozes, imagens e interesses organizacionais ampliados por visões opostas. E nos estudos sequenciais, os pesquisadores cultivam diversas representações para informar uns aos outros, propositalmente, os resultados de um estudo sobre determinado paradigma que fornecem insumos para estudos subsequentes. Utilizando lentes em sucessão, procuram refinar seus pontos de vista distintos, porém complementares.

Como a discussão metodológica, então, guarda relação com discussões paradigmáticas, no intuito de empreender o caminho para responder a questão da presente pesquisa, foi realizada uma análise relativa à postura paradigmática prevalecente nos 174 artigos analisados.

\subsection{Postura paradigmática prevalecente nos artigos}

Para abordar a postura paradigmática prevalecente nos artigos, foi realizada uma análise do discurso empregado pelos autores dos artigos. Os critérios considerados para a classificação das pesquisas foram as características do positivismo e do interpretativismo abordadas no item 2 no referencial teórico desta pesquisa. Como já foi ressaltado, optamos por utilizar apenas estes dois paradigmas, não desconsiderando a existência de outros. O que buscamos foram características que aproximassem os estudos a cada um dos dois paradigmas. Adicionalmente 
às características de ambos os paradigmas que foram apresentadas no referencial, utilizamos como critério adicional de análise as diferenças existentes entre os pressupostos das abordagens subjetivas (relacionadas aqui ao paradigma interpretacionista) e objetivas (relacionadas ao paradigma positivista) nas ciências sociais, sistematizadas por Mendonça (2002), com base em Morgan e Smircich (1980), como se pode observar na figura 2.

\section{Figura 2}

\section{Rede de pressupostos básicos caracterizando o debate subjetivismo- objetivismo dentro da ciência social}

\begin{tabular}{|c|c|c|c|c|c|c|}
\hline \multicolumn{7}{|c|}{ Rede de pressupostos básicos caracterizando o debate subjetivismo-objetivismo dentro da ciência social } \\
\hline \multirow[b]{2}{*}{$\begin{array}{l}\text { Pressupostos } \\
\text { ontológicos } \\
\text { centrais }\end{array}$} & \multicolumn{3}{|c|}{ Abordagens subjetivas } & \multicolumn{3}{|c|}{ Abordagens objetivas } \\
\hline & $\begin{array}{c}\text { Realidade como } \\
\text { uma projeção } \\
\text { da imaginação } \\
\text { humana }\end{array}$ & $\begin{array}{c}\text { Realidade como } \\
\text { uma construção } \\
\text { social }\end{array}$ & $\begin{array}{l}\text { Realidade } \\
\text { como um } \\
\text { campo de } \\
\text { discurso } \\
\text { simbólico }\end{array}$ & $\begin{array}{l}\text { Realidade } \\
\text { como um } \\
\text { campo } \\
\text { contextual de } \\
\text { informação }\end{array}$ & $\begin{array}{l}\text { Realidade } \\
\text { como um } \\
\text { processo } \\
\text { concreto }\end{array}$ & $\begin{array}{l}\text { Realidade } \\
\text { como uma } \\
\text { situação } \\
\text { concreta }\end{array}$ \\
\hline $\begin{array}{c}\text { Pressupostos } \\
\text { sobre a } \\
\text { natureza } \\
\text { humana }\end{array}$ & $\begin{array}{l}\text { Homem como } \\
\text { puro espírito, } \\
\text { consciência, ser }\end{array}$ & $\begin{array}{l}\text { Homem como } \\
\text { um construtor } \\
\text { social, o criador } \\
\text { de símbolos }\end{array}$ & $\begin{array}{l}\text { Homem como } \\
\text { um ator, o } \\
\text { usuário de } \\
\text { símbolos }\end{array}$ & $\begin{array}{l}\text { Homem } \\
\text { como um } \\
\text { processador de } \\
\text { informações }\end{array}$ & $\begin{array}{l}\text { Homem como } \\
\text { um adaptador }\end{array}$ & $\begin{array}{l}\text { Homem } \\
\text { como um } \\
\text { respondente }\end{array}$ \\
\hline $\begin{array}{c}\text { Estâncias } \\
\text { epistemológicas } \\
\text { básicas }\end{array}$ & $\begin{array}{c}\text { Para obter } \\
\text { insight } \\
\text { fenomenológico, } \\
\text { revelação }\end{array}$ & $\begin{array}{l}\text { Para entender } \\
\text { como a } \\
\text { realidade social } \\
\text { é criada }\end{array}$ & $\begin{array}{l}\text { Para entender } \\
\text { padrões do } \\
\text { discurso } \\
\text { simbólico }\end{array}$ & $\begin{array}{l}\text { Para mapear o } \\
\text { contexto }\end{array}$ & $\begin{array}{c}\text { Para estudar } \\
\text { os sistemas, os } \\
\text { processos, a } \\
\text { mudança }\end{array}$ & $\begin{array}{c}\text { Para construir } \\
\text { uma ciência } \\
\text { positivista }\end{array}$ \\
\hline $\begin{array}{l}\text { Algumas } \\
\text { metáforas } \\
\text { permitidas }\end{array}$ & Transcendental & $\begin{array}{c}\text { Jogo da } \\
\text { linguagem, } \\
\text { realização, texto }\end{array}$ & Teatral, cultural & Cibernética & Orgânica & Mecânica \\
\hline $\begin{array}{c}\text { Métodos de } \\
\text { pesquisa }\end{array}$ & $\begin{array}{c}\text { Exploração } \\
\text { de pura } \\
\text { subjetividade }\end{array}$ & Hermenêutica & $\begin{array}{l}\text { Análise } \\
\text { simbólica }\end{array}$ & $\begin{array}{l}\text { Contextual das } \\
\text { Gestalten }\end{array}$ & Análise histórica & $\begin{array}{c}\text { Experimentos } \\
\text { de laboratério, } \\
\text { surveys }\end{array}$ \\
\hline $\begin{array}{l}\text { Alguns } \\
\text { exemplos de } \\
\text { pesquisa }\end{array}$ & Fenomenologia & Etnometodologia & $\begin{array}{l}\text { Teoria da ação } \\
\text { social }\end{array}$ & Cibernética & $\begin{array}{l}\text { Teoria dos } \\
\text { sistemas } \\
\text { abertos }\end{array}$ & $\begin{array}{c}\text { Behaviorismo } \\
\text { da teoria da } \\
\text { aprendizagem } \\
\text { social }\end{array}$ \\
\hline
\end{tabular}

Fonte: Mendonça (2002:6).

Além desses critérios, é importante enfatizar que não assumimos uma relação exclusiva entre a pesquisa quantitativa e o positivismo, e a pesquisa qualitativa e o interpretativismo, já que abordamos no item 2 a visão de Snape e Spencer (2003) de que não há uma distinção absolutamente clara entre essas perspectivas. Há uma associação entre estes construtos, como demonstramos, mas consideramos, por exemplo, que o método de coleta de dados (como questionário estruturado e entrevistas) não seja, por si só, um indício absoluto de uma postura 
positivista e/ou interpretativista. Por esse motivo, foi realizada uma análise de conteúdo de todos os artigos.

Assim, a análise permitiu que chegássemos à distribuição relativa à postura paradigmática adotada descrita na tabela 3.

Tabela 3

Postura paradigmática prevalecente nos artigos

\begin{tabular}{|ccccc|}
\hline \multicolumn{5}{c|}{ Postura paradigmática prevalecente nos artigos } \\
\hline $\begin{array}{c}\text { Divisão temática } \\
\text { do evento }\end{array}$ & $\begin{array}{c}\text { Prtigos - } \\
\text { Triangulação }\end{array}$ & $\begin{array}{c}\text { Predomínio da } \\
\text { visão positivista na } \\
\text { pesquisa }\end{array}$ & $\begin{array}{c}\text { Predomínio da visão } \\
\text { interpretativa na } \\
\text { pesquisa }\end{array}$ & $\begin{array}{c}\text { Equilíbrio entre as visões } \\
\text { positivista e interpretativa na } \\
\text { pesquisa }\end{array}$ \\
\hline GPR & 26 & $55 \%$ & $0 \%$ & $45 \%$ \\
MKT & 29 & $78 \%$ & $0 \%$ & $22 \%$ \\
APS & 33 & $51 \%$ & $0 \%$ & $49 \%$ \\
ADI & 12 & $100 \%$ & $0 \%$ & $0 \%$ \\
EPQ & 16 & $33 \%$ & $17 \%$ & $50 \%$ \\
EOR & 18 & $44 \%$ & $50 \%$ & $6 \%$ \\
ESO & 17 & $100 \%$ & $0 \%$ & $0 \%$ \\
CONT & 11 & $100 \%$ & $0 \%$ & $0 \%$ \\
GOL & 6 & $100 \%$ & $0 \%$ & $0 \%$ \\
GCT & 6 & $50 \%$ & $0 \%$ & $50 \%$ \\
TOTAL & 174 & $67 \%$ & $7 \%$ & $26 \%$ \\
\hline
\end{tabular}

Em decorrência do que já foi comentado, de que há um enfoque maior, nos artigos, nos resultados quantitativos das pesquisas, observa-se também que há um predomínio de uma visão positivista de ciência. Não se assume aqui que os estudos sejam puramente positivistas ou interpretativistas, apenas se considera que os mesmos guardem pressupostos que se aproximam mais de uma ou de outra corrente, o que não necessariamente faz com que possam ser considerados unicamente dessas duas perspectivas. Tendo em conta as características do positivismo e do interpretativismo destacadas no item 2 deste artigo, observou-se que há, de forma significativa, um predomínio da visão positivista nos estudos analisados, o que ocorreu em $67 \%$ dos estudos analisados (tabela 3). Em contrapartida, apenas em 7\% dos artigos predominava uma visão interpretativa. O equilíbrio entre as visões positivistas e interpretativas, que ocorreu principalmente entre os estudos que demonstraram os resultados qualitativos e quantitativos de forma integrada (na tabela 2, observa-se que $27 \%$ apresentaram os resultados quantitativos e qualitativos de forma integrada, enquanto há um equilíbrio entre as visões positivista e interpretativa em $26 \%$ dos estudos, como se observa na tabela 3 ). Não se defende aqui que o equilíbrio seja o ideal, apenas se destaca como, mesmo em combinação de métodos, a visão positivista continua a prevalecer nos estudos em administração. Ou seja, 
o mainstream continua produzindo significativamente seus efeitos sobre os pesquisadores da área. Nesse sentido, começa-se a desconstruir a defesa da triangulação metodológica enquanto necessariamente associada ao multiparadigmatismo, desconstrução esta que se efetiva no próximo subitem.

Antes ainda, continuando a presente discussão, o discurso empregado pelos autores permite revelar o predomínio da visão positivista em vários casos. Um artigo da divisão de APS, por exemplo, tinha como objetivo encontrar formas de se medir o capital social, lamentando que "por ser um conceito de origem recente, ainda não existem modelos quantitativos nem qualitativos aceitos como parâmetros definitivos para se medir capital social" (Artigo APS). O mesmo artigo demonstra o estabelecimento de "tipologias de confiança", ou seja, definindo tipos e modelos para um constructo que seria mais característico de visões interpretativas da realidade. Abarcando uma visão típica de interpretativistas, poder-se-ia questionar: como estabelecer tipos de confiança ou, ainda, como medir o capital social? Notadamente, as visões positivistas e interpretativas assumem pressupostos bem diferentes da realidade, o que poderia contribuir para a já discutida consideração de que não possam ser combinadas. Contudo, considera-se que seja apenas uma questão de dificuldade (Kuhn, 2000; Duarte, 2006) e não impossibilidade de comunicação (Hoyningen-Huene, 1993).

No mesmo sentido, um artigo da divisão de ESO quer "mensurar o comportamento de indivíduos", enquanto outro da mesma divisão descreve como principais contribuições de seu trabalho o estabelecimento de modelos e de metodologias padronizados para avaliação de competitividade e de fatores críticos de sucesso para um setor mercadológico, afirmando que

Os resultados do trabalho contemplam contribuições nos planos metodológico, teórico e empírico. No plano metodológico, o trabalho desenvolve uma metodologia diferenciada de seleção e identificação de Fatores Críticos de Sucesso. No plano teórico é proposto um modelo de avaliação de competitividade [...]. No plano empírico o trabalho seleciona e especifica como Fatores Críticos de Sucesso para o setor frutícola, a [...] (Artigo ESO).

Há ainda vários outros trechos que demonstram o discutido predomínio da visão positivista na pesquisa. Mas, por questões de limitações de espaço no artigo, segue-se a discussão decorrente das até então realizadas: em que sentido a triangulação é utilizada nesses estudos?

\subsection{Os sentidos da utilização da triangulação: validação convergente ou conversação paradigmática?}

Os resultados até então discutidos já permitem que se trace um panorama que enfraquece a utilização da triangulação nas pesquisas em Administração no sentido de multiparadigmatismo, o que se confirma com a análise específica sobre a forma com que a mesma foi empregada nestes estudos, cujo resultado pode ser observado na tabela 4. 
Tabela 4

\section{Sentido em que a triangulação foi utilizada}

\begin{tabular}{|ccccc|}
\hline $\begin{array}{c}\text { Divisão temática } \\
\text { do evento }\end{array}$ & $\begin{array}{c}\text { Artigos- } \\
\text { triangulação }\end{array}$ & $\begin{array}{c}\text { Validação convergente } \\
\text { (predomina o sentido } \\
\text { de complementação) }\end{array}$ & $\begin{array}{c}\text { Validação convergente } \\
\text { (predomina desejo de } \\
\text { aumentar confiabilidade } \\
\text { da pesquisa) }\end{array}$ & $\begin{array}{c}\text { Conversação entre duas } \\
\text { visões da realidade } \\
\text { (como conversação } \\
\text { paradigmática) }\end{array}$ \\
\hline GPR & 26 & $50 \%$ & $30 \%$ & $20 \%$ \\
MKT & 29 & $45 \%$ & $33 \%$ & $22 \%$ \\
APS & 33 & $50 \%$ & $25 \%$ & $25 \%$ \\
ADI & 12 & $100 \%$ & $0 \%$ & $0 \%$ \\
EPQ & 16 & $50 \%$ & $17 \%$ & $33 \%$ \\
EOR & 18 & $50 \%$ & $25 \%$ & $25 \%$ \\
ESO & 17 & $40 \%$ & $60 \%$ & $0 \%$ \\
CONT & 11 & $75 \%$ & $25 \%$ & $0 \%$ \\
GOL & 6 & $75 \%$ & $25 \%$ & $0 \%$ \\
GCT & 6 & $33 \%$ & $67 \%$ & $0 \%$ \\
TOTAL & 174 & $53 \%$ & $30 \%$ & $17 \%$ \\
\hline
\end{tabular}

Como se observa, a triangulação tem sido adotada com algumas definições presentes no item 3 deste artigo, nas quais assume o sentido estrito de validação convergente pela maioria dos autores dos artigos analisados, 83\% (53\% em um sentido mais próximo do objetivo de complementação e 30\% explicitamente com o objetivo de aumentar a validade e a confiabilidade da pesquisa), enquanto em apenas $17 \%$ dos artigos observou-se, de fato, o estabelecimento de uma conversação entre duas visões da realidade e do conhecimento científico.

Assim, o objetivo de validação das pesquisas se tornou o principal alvo dos pesquisadores que optaram pela combinação de métodos. ${ }^{2}$ A combinação como caminho metodológico para o multiparadigmatismo ainda é adotada de forma tímida pelos pesquisadores, não chegando nem a ser observada em algumas divisões temáticas do encontro. Confirmando o fato de que a divisão de EPQ apresentou de forma mais integrada os resultados qualitativos e quantitativos, como destacado no item 5.1, observa-se que, em termos percentuais, foi a divisão que mais empreendeu a conversação paradigmática, o que ocorreu em 33\% de seus

\footnotetext{
${ }^{2}$ Não se defende aqui que a validade não possa ser um objetivo de pesquisadores qualitativos, por exemplo. No entanto, nesse contexto, ela pode assumir sentido diferente. Ollaik e Ziller (2011) afirmam que a concepção de validade é originalmente de natureza positivista, tendo sido adaptada ao longo do tempo para o contexto da pesquisa qualitativa, assumindo um sentido mais amplo, pormenorizado e menos mensurável quantitativamente.
} 
artigos, o que reforça a afirmação de que a integração de métodos qualitativos e quantitativos, se bem trabalhada, possa ser o caminho para estudos multiparadigmáticos.

Nos estudos que objetivaram a validação convergente, há expressões que indicam que o resultado de uma etapa "justificou" o resultado da outra etapa. O sentido de complementaridade (observado em 53\% dos artigos) fica claro em trechos como "por sua vez, a abordagem qualitativa foi adotada para dar base e parametrizar os resultados quantitativos, visando a uma melhor análise geral do caso"; "optou-se pelo uso de métodos tanto qualitativos como quantitativos [...] como forma de analisar a interação entre variáveis presentes no fenômeno estudado e compreendê-lo mais profundamente"; "os dados foram coletados em duas etapas de modo a se complementarem" (Artigos APS); "em função do baixo retorno, usou-se, para complementar a pesquisa, a técnica da análise de discurso [...] originalmente não prevista" (Artigo CON); e "enquanto a amostra para a abordagem qualitativa foi composta por 23 [...] funcionários, conduzida para permitir a identificação de nuances não reveladas pela pesquisa quantitativa e aprofundar o estudo dos pontos mais relevantes" (Artigo GPR).

$\mathrm{O}$ intuito de aumentar a validade e confiabilidade das pesquisas (observado em $30 \%$ dos artigos) também fica claro em outros trechos, tais como "a triangulação de dados permitiu verificar critérios de coerência e consistência dos dados coletados, e a observância desses critérios tornou-se importante para assegurar a qualidade dos resultados obtidos" (Artigo APS); "a análise das entrevistas objetivou ratificar as evidências de troca e criação de valor, encontradas pelo questionário" (Artigo ESO)"; e "a segunda implicação foi a verificação, por meio da análise dos dados, de que somente três dos cinco elementos identificados no grupo de foco [...] apresentou [sic] diferença estatística significativa" (Artigo GCT). Outro artigo da divisão de GPR utiliza a técnica Delphi ${ }^{3}$ nas entrevistas em profundidade, o que destaca sua preocupação com a validação convergente até mesmo na etapa qualitativa. Um artigo da divisão de MKT fala, inclusive, diretamente do termo: "a validação convergente foi basicamente apoiada pelo fato de que cada item, sem exceções, apresentou coeficientes fatoriais altos e significativos".

Já nos estudos que empreenderam, de fato, a conversação paradigmática (17\% dos artigos), observa-se uma preocupação igualmente relevante, por exemplo, com a percepção de sujeitos entrevistados e com dados quantitativos coletados, como ocorre em um dos artigos de APS, no qual não se observa um sentido e conotação de validação convergente à combinação de métodos. Um artigo da divisão de EPQ, por exemplo, apresenta uma conclusão que guarda relação com a discussão aqui realizada:

\footnotetext{
3 "Em linhas gerais, o método Delphi consulta um grupo de especialistas a respeito de eventos futuros através de um questionário, que é repassado continuadas vezes até que seja obtida uma convergência das respostas, um consenso, que representa uma consolidação do julgamento intuitivo do grupo. Pressupõe-se que o julgamento coletivo, ao ser bem organizado, é melhor do que a opinião de um só indivíduo. O anonimato dos respondentes, a representação estatística da distribuição dos resultados, e o feedback de respostas do grupo para reavaliação nas rodadas subsequentes são as principais características deste método" (Wright e Giovinazzo, 2000:54).
} 
Conclui-se que existe uma contribuição efetivamente para o conhecimento, descrição e explicação de fenômenos sociais quando se faz a utilização das técnicas de forma complementar, oportunizando evidenciar situações não postas na realidade, por estarem no âmbito dos indivíduos e/ou grupos sendo estes influenciadores dos resultados de pesquisas sociais. As técnicas quantitativas garantem a precisão dos resultados [...]. Por outro lado, as técnicas qualitativas reconhecem os atores sociais como sujeitos singulares que produzem conhecimentos e práticas como modo de vida, crenças e valores através das experiências sociais (Artigo EPQ).

Como características observadas nos estudos que empreenderam conversações paradigmáticas, aponta-se uma articulação empreendida entre as perspectivas distintas adotadas nos estudos e uma habilidade significativa dos autores em articular bem duas dimensões distintas da realidade. Um artigo da divisão de GPR, por exemplo, inclusive admite adotar o paradigma da complexidade (Morin, 2001), que pode se associar a uma perspectiva multimétodos, além de declarar que assume uma compreensão dialógica da realidade.

Desse modo, a resposta à questão de pesquisa é que a triangulação nas pesquisas em administração, na verdade, não tem sido utilizada de forma associada ao multiparadigmatismo pela maior parte dos estudos, como era defendida sua aplicabilidade por Teixeira e Nascimento (2010) nos estudos publicados nos anais do EnAnpad.

\section{Discussões}

Apresentam-se nesta seção discussões por uma necessidade dos autores em esclarecer alguns aspectos relativos à defesa do multiparadigmatismo nas pesquisas em administração, já que este se trata de um tema que gera ainda debates significativos.

Em primeiro lugar, pretendemos esclarecer nosso posicionamento teórico ao defender o multiparadigmatismo, considerando a possibilidade de que este não tenha ficado claro ao longo do artigo. Consideramos tal discussão importante porque os discursos dizem respeito às posições dos sujeitos (Foucault, 2008; Fairclough, 1995). Nesse sentido, a defesa que fizemos em relação ao multiparadigmatismo integra-se a uma rede discursiva, considerando ainda que a total objetividade do pesquisador em uma análise só seria possível se houvesse a neutralização de seus interesses econômicos, sociais, culturais e simbólicos (Maton, 2003).

E de que local falamos nessa rede discursiva? De acordo com avaliadores do artigo em sua versão submetida a congresso da Anpad, pode-se considerar difícil assumir a visão multiparadigmática sem que se adote uma narrativa pós-modernista. Nessa concepção, o conhecimento seria visto como uma grande narrativa. De fato, esta foi a concepção adotada por Cox e Hassard (2005) ao abordarem a triangulação no contexto da pesquisa organizacional.

No entanto, assumimos o conhecimento como uma narrativa, e não como uma grande ou metanarrativa. Nesse aspecto, nos aproximamos mais de uma visão pós-estruturalista do que propriamente pós-modernista. Ao invés de ciência — a ciência —, assumimos a existência de ciências. 
Não defendemos o multiparadigmatismo por meio de uma narrativa pós-moderna porque corroboramos Meyerhoff (2010), o qual afirma que a natureza do pós-modernismo como paradigma científico é discutível, e com Lather (1991), que afirma que o pós-modernismo é apenas um nome que representa a crise de confiança em relação ao sistema ocidental moderno. Além disso, diz respeito a uma abordagem teórica que é adepta do relativismo, segundo Paula, Maranhão e Barros (2009). Nessa concepção, tudo seria justificável.

Aproximamo-nos mais de uma concepção pós-estruturalista (Peters, 2000), já que assumimos o conhecimento como uma narrativa, e não uma grande narrativa. O pós-estruturalismo, como resposta filosófica ao estruturalismo, tem como objetivo o descentramento das estruturas, criticando a existência de uma Verdade universal e única (Peters, 2000), apresentando um descrédito em relação às metanarrativas (Meyerhoff, 2010).

Defendemos o multiparadigmatismo, mas não "a todo custo". Nesse sentido, assim como Bourdieu (1989) afirma que não se deve confundir o necessário rigor metodológico com rigidez, não se deve confundir nossa defesa pela combinação de métodos e pelo multiparadigmatismo como uma defesa incondicional que acredita que esta seja a melhor alternativa para se realizar estudos no âmbito da administração (defendemos, sim, seus potenciais benefícios para a pesquisa). Pois há variados estudos, objetos, sujeitos, teorias e pesquisadores, não havendo um único caminho viável para se realizarem pesquisas.

Em termos populares, defendemos também que não se deve confundir liberdade metodológica/paradigmática com libertinagem metodológica/paradigmática. A liberdade a que nos referimos diz respeito ao fato de acreditarmos que existem ciências e não uma grande ciência (a ciência universal). Nesse aspecto, a subjetividade do sujeito-pesquisador, não neutro axiologicamente, pode levá-lo a caminhos de pesquisa que impliquem a conversação entre paradigmas, o que acreditamos ser positivo dentro de um contexto de ciência no qual há um mainstream ainda significativo que limita possibilidades de conversações.

Por fim, nessa discussão que precede as considerações finais, esclarecemos que não pretendemos aqui elaborar uma receita de como devam ser realizados estudos multiparadigmáticos. Se o fizéssemos, cairíamos no risco de propormos um modelo, uma grande narrativa, um modus operandi para estudos multiparadigmáticos, o que não é nossa pretensão. Ademais, quantos não podem ser os paradigmas de pesquisa adotados pelos pesquisadores? Como poderíamos elaborar uma receita que se aplicasse a todos os tipos de combinações possíveis?

\section{Considerações finais}

O presente estudo permitiu, entre outras questões, observar como a combinação de métodos nas pesquisas em administração tem sido adotada principalmente no intuito de validação convergente, não implicando necessariamente conversações efetivas entre diferentes visões de mundo e de conhecimento científico. O que se observa é sua aplicação principalmente em estudos nos quais predomina, em termos epistemológicos, uma visão positivista e, em termos metodológicos, uma postura nomotética. 
Assim, este artigo traz à tona novamente o predomínio positivista que ainda impera na administração, embora disfarçado por autores que lançam mão da triangulação entre métodos. Seria essa uma busca pela atualização do positivismo? Estaríamos frente a um neopositivismo (já que se discute, por exemplo, um neofuncionalismo, como o faz Crubellate (2007))? Nesse sentido, a triangulação também é buscada para qualificar os dados quantitativos, buscando um perfil novamente positivista? Pois se observa uma conotação de combinação de métodos dentro de pressupostos de rigor científico, validade e confiabilidade, o que se aproxima mais do paradigma positivista de pesquisa do que do paradigma interpretativo. Assim, o predomínio do mainstream nos estudos organizacionais, apontado por autores como Caldas e Fachin (2005), continua sendo significativo mesmo entre os pesquisadores multimétodos.

Não se quer dizer que a simples combinação de métodos não seja válida e não enriqueça uma pesquisa. O que se quis investigar neste estudo é o modo como a questão paradigmática se faz presente nessa combinação. Porém, não se nega a postura adotada pelos autores no presente artigo, no qual se defende a relevância da tentativa de se combinarem perspectivas em um mesmo estudo e no qual a observada adoção dos métodos qualitativos apenas como fonte de informações para um objetivo maior, que é o método quantitativo, é considerada preocupante. Reforça-se que o multiparadigmatismo seja uma alternativa significativa para lidar com a complexidade dos fenômenos sociais, já que

[...] precisamos dar conta de que o que todo conceito faz é excluir, tanto quanto incluir; ignorar, tanto quanto concentrar-se; entregar para a obscuridade, tanto quanto trazer para os refletores. Conceitos passam dos limites. E em lugar algum isso acontece mais do que no conceito de paradigma. (Burrell, 2007:442, grifo do autor).

Relativamente à triangulação, sugerimos a utilização do termo combinação de métodos, o que abriria espaço para outras perspectivas metodológicas, tais como as que se relacionam a autores que defendem o uso não de uma "geometria plana" (como o triângulo) para se pensar essa combinação, e sim a utilização de cristais, como Richardson (1994), que descreve o cristal como multidimensional, e o que nós vemos depende de nosso ângulo de análise, metáfora esta que parece apropriada à defesa do multiparadigmatismo, embora não assumamos uma narrativa pós-moderna como faz o autor ao defender o cristal.

Cabe ainda uma ressalva a todas as afirmações e defesas aqui realizadas, a de que a adequação dos métodos ao problema de pesquisa, a seus sujeitos ou objetos, e à postura do pesquisador seja priorizada. Contudo, não uma adequação que seja determinada por lentes de análise que priorizem o positivismo e/ou o interpretativismo, por si só, mas lentes que permitam buscar formas de superação de históricas incomensurabilidades paradigmáticas.

Além dos resultados obtidos com a análise dos artigos que utilizam a combinação de métodos, o estudo contribui no sentido de tratar de um tema com potencial para se discutir a relação entre métodos e pressupostos epistemológicos no contexto dos estudos organizacionais. Por fim, ficamos tentados a considerar como limitação da pesquisa a subjetividade inerente ao próprio processo realizado de análise dos 174 artigos que fizeram o uso da triangu- 
lação. Porém, se assim o fizermos, cria-se uma contradição com a postura adotada no estudo. Dessa forma, apenas aponta-se a subjetividade envolvida nas análises e se sugere, para futuros estudos, uma análise mais aprofundada dos artigos que empreenderam a conversação paradigmática (os artigos que respondem por $17 \%$ do total de 174), para que contribuições mais específicas sejam geradas para a discussão acerca do multiparadigmatismo nas pesquisas.

\section{Referências}

BANSAL, P.; CORLEY, K. From the editors - the coming of age for qualitative research: embracing the diversity of qualitative methods. Academy of Management Journal, v. 54, n. 2, p. 233-237, 2011.

BARDIN, L. Análise de conteúdo. Lisboa: Edições 70, 2004.

BASTOS FILHO, J.B. Sobre os paradigmas de Kuhn, o problema da incomensurabilidade e o confronto com Popper. Acta Scientiarum, v. 22, n. 5, p. 1297-1309, 2000. Disponível em: <www. periodicos.uem.br/ojs/index.php/ActaSciTechnol/article/viewPDFInterstitial/3064/2215>. Acesso em: 15 jun. 2009.

BELLOQUIM, A.; LACOMBE, B. Administração: uma disciplina esquisofrênica?: In: SEMEAD, VI, São Paulo, 2003. Anais...

BLAIKIE, N.W.H. A critique of the use of triangulation in social research. Quality and Quantity, v. 25, n. 2, p. 115-136, May 1991.

BOURDIEU, P. O poder simbólico. Lisboa: Difel, 1989.

BRYMAN, A. Barriers to integrating quantitative and qualitative research. Journal of Mixed Methods Research, v. 1, n. 1, p. 8-22, Jan. 2007.

BURRELL, G. Ciência normal, paradigmas, metáforas, discursos e genealogia da análise. In: CLEGG, S.R.; HARDY, C.; NORD, W.R. (Org.). Handbook de estudos organizacionais. São Paulo: Atlas, 2007.

CALDAS, M.P.; FACHIN, R. Paradigma funcionalista: desenvolvimento de teorias e institucionalismo nos anos 1980 e 1990. Revista de Administração de Empresas, v. 45, n. 2, 2005.

CLEGG, S.R.; MORGAN, G. Sociological paradigms and organizational analysis. London: Heinemann, 1979.

COX, J.W.; HASSARD, J. Triangulation in organizational research: a re-presentation. Organization, v. 12, n. 1, p. 109-133, 2005.

CRESWELL, J.W.; TASHAKKORI, A. Editorial: developing publishable mixed methods manuscripts. Journal of Mixed Methods Research, v. 1, n. 2, p. 107-111, Apr. 2007.

CRUBELLATE, J.M. Três contribuições conceituais neofuncionalistas à teoria institucional em organizações. Revista de Administração Contemporânea, ed. especial, p. 199-222, 2007. 
CZARNIAWSKA, B. Who is afraid of incommensurability? Organization, v. 5, n. 2, p. 273-279, 1998.

DOWNEY, H.K.; IRELAND, R.D. Quantitative versus qualitative: the case of environmental assessment in organizational studies. Administrative Science Quarterly, v. 24, n. 4, p. 630-637, Dec. 1979.

DUARTE, T.R. Um olhar sobre os últimos trabalhos de T. Kuhn. In: XXI ENCONTRO REGIONAL DE HISTÓRIA ANPUH: Usos do Passado, XXI, Rio de Janeiro, 2006. Anais eletrônicos... Disponível em: <www.rj.anpuh.org/Anais/2006/conferencias/Tiago\%20Ribeiro\%20Duarte.pdf>. Acesso em: 15 jun. 2009.

DUFFY, M.E. Methodological triangulation: a vehicle for merging quantitative and qualitative research methods. Journal of Nursing Scholarship (on-line), v. 19, n. 3, Oct. 2007. Disponível em: $<$ www3.interscience.wiley.com/journal/120024498/abstract?CRETRY $=1 \&$ SRETRY $=0>$. Acesso em: 18 jun. 2009.

FAIRCLOUGH, N. Critical discourse analysis: the critical study of language. London: Longman, 1995.

FEITOSA, I.L.; POPADIUK, H.D. Estruturação de pesquisas acadêmicas: a perspectiva multiparadigmática. In: ENCONTRO NACIONAL DA ANPAD, XXXIII, São Paulo, 2009. Anais... Rio de Janeiro: Anpad, 2009.

FOUCAULT, M. A arqueologia do saber. Rio de Janeiro: Forense Universitária, 2008.

GODOY, A.S. Pesquisa qualitativa: tipos fundamentais. Revista de Administração de Empresas, São Paulo, v. 35, n. 3, p. 20-29, maio/jun. 1995.

GREENE, J.C.; CARACELLI, V.J. (Ed.). Advances in mixed-method evaluation: the challenges and benefits of integrating diverse paradigms. San Francisco: Jossey-Bass, 1997.

GREENE, J.C.. Is mixed methods social inquiry a distinctive methodology? Journal of Mixed Methods Research, v. 2, n. 1, p. 7-22, Jan. 2008.

HOYNINGEN-HUENE, P. Reconstructing scientific revolutions: Thomas S. Kuhn's philosophy of science. Tradução de Alexander Levine. Chicago: The University of Chicago Press, 1993.

JACKSON, N.; CARTER, P. In defense of paradigm incommensurability. Organization Studies, v. 12, n. 1, p. 109-127, 1991.

JICK, T.D. Mixing qualitative and quantitative methods: triangulation in action. Administrative Science Quarterly, v. 24, n. 4, p. 602-611, Dec. 1979. Disponível em: < http://web.ebscohost.com/ ehost/pdf?vid=8\&hid=103\&sid=e04573e9-21fa-414b-83cf-d7f3afe44da0\%40sessionmgr11 > . Acesso em: 15 jun. 2009.

JOHNSON, R.B.; ONWUEGBUZIE, A.J. Mixed methods research: a research paradigm whose time has come. Educational Researcher, v. 33, n. 7, p. 14-26, Oct. 2004.

KUHN, T.S. The road since structure: philosophical essays, 1970-1993, with an autobiographical interview. Edition: James Conant and John Haugeland. Chicago: The University of Chicago Press, 2000. 
KUHN, T.S. A estrutura das revoluções científicas. São Paulo: Perspectiva, 2005.

KUHN, T.S. The structure of scientific revolutions. Chicago: University Press, 1962.

LATHER, P. Getting smart: feminist research and pedagogy with/in the postmodern. New York: Routledge/American Educational Studies Association, 1991.

LAVILLE, C.; DIONNE, J. A construção do saber: manual de metodologia de pesquisa em ciências humanas. Porto Alegre: Artmed, 1999.

LEWIS, J.; RITCHIE, J. Generalising from qualitative research. In: RITCHIE, J.; LEWIS, J. (Ed.). Qualitative research practice: a guide for social science students and researchers. London: Sage Publications, 2003. p. 263-286.

LEWIS, M.W.; GRIMES, A.J. Metatriangulação: a construção de teorias a partir de múltiplos paradigmas. Revista de Administração de Empresas, São Paulo, v. 45, n. 1, p. 72-91, jan./mar. 2005.

LIMA, L.A. de. A representação das múltiplas dimensões paradigmáticas no estudo da administração: um ensaio sobre os limites contidos nas defesas paradigmáticas excludentes. Revista de Administração Contemporânea, v. 15, n. 2, p. 198-208, 2011.

MATHISON, S. Why triangulate? Educational Researcher, v. 17, n. 2, p. 13-17, 1988. Disponível em: <http://edr.sagepub.com/cgi/reprint/17/2/13>. Acesso em: 18 jun. 2009.

MATON, K. Reflexivity, relationism \& research: Pierre Bourdieu and the epistemic conditions of social scientific knowledge. Space \& Culture, London, v. 6, n. 1, p. 52-65, Feb. 2003. Disponível em: $<$ http://sac.sagepub.com/cgi/reprint/6/1/52>. Acesso em: 26 mar. 2010.

MATTOS, P.L.C.L. "Os resultados desta pesquisa (qualitativa) não podem ser generalizados": pondo os pingos nos is de tal ressalva. Cadernos Ebape.BR, v. 9, ed. especial, p. 450-468, jul. 2011.

MAXWELL, J.A.; LOOMIS, D. M. Mixed methods design: an alternative approach. In: TASHAKKORI, A.; TEDDLIE, C. (Ed.). Handbook of mixed methods in social and behavioral research. Thousand Oaks: Sage, 2003.

MENDONÇA, J.R.C. de. Interacionismo simbólico: uma sugestão metodológica para a pesquisa em Administração. REAd, v. 8, n. 2, mar./abr. 2002.

MEYERHOFF, J. Bald ambition: a critique of Ken Wilber's theory of everything. New York: Inside the Curtain Press, 2010.

MORGAN, D.L. Paradigms lost and pragmatism regained: methodological implications of combining qualitative and quantitative methods. Journal of Mixed Methods Research, v. 1, n. 1, p. 48-76, Jan. 2007.

MORGAN, G.; SMIRCICH, L. The case for qualitative research. The Academy of Managemente Review, v. 5, n. 4, p. 491-500, Oct. 1980. Disponível em: <http://conium.org/ maccoun/PP279_Morgan. pdf>. Acesso em: 15 jun. 2009.

MORIN, E. Introdução ao pensamento complexo. Lisboa: Piaget, 2001. 
MORSE, J.M. Approaches to qualitative-quantitative methodological triangulation. Nursing Research, v. 40, n. 1, p. 120-132, 1991.

NEVES, J.L. Pesquisa qualitativa: características, usos e possibilidades. Caderno de Pesquisas em Administração, São Paulo, v. 1, n. 3, 2. sem, 1996. Disponível em: <www.ead.fea.usp.br/cad-pesq/ arquivos/c03-art06.pdf>. Acesso em: 18 jun. 2009.

OLLAIK, L.G.; ZILLER, H. Distintas concepções de validade em pesquisas qualitativas. In: ENCONTRO NACIONAL DA ANPAD, XXXV, Rio de Janeiro, 2011. Anais... Rio de Janeiro: Anpad, 2011.

OTTOBONI, C. Perspectivas de triangulação entre diferentes paradigmas na pesquisa em administração. In: ENCONTRO NACIONAL DA ANPAD, XXXIII, São Paulo, 2009. Anais... Rio de Janeiro: Anpad, 2009.

PAULA, A.P.P.; MARANHÃO, C.M.S.A.; BARROS, A.N. Pluralismo, pós-estruturalismo e "gerencialismo engajado": os limites do movimento critical management studies. Cadernos Ebape.BR, v. 7, n. 3, p. 393-404, 2009.

PETERS, M. Pós-estruturalismo e filosofia da diferença. Belo Horizonte: Autêntica, 2000.

POPE, C.; MAYS, N. Reaching the parts other methods cannot reach: an introduction to qualitative methods in health and health service research. British Medical Journal, n. 311, p. 42-45, 1995.

REED, M. Teorização organizacional: um campo historicamente contestado. In: CALDAS, M.; FACHIN, R.; FISCHER, T. (Org.). Handbook de estudos organizacionais. São Paulo: Atlas, 2007.

RICHARDSON, L. Writing: a method of inquiry. In: DENZIN, N.K.; LINCOLN, Y.S. Handbook of qualitative research. Thousand Oaks: Sage, 1994. p. 516-529.

RITCHIE, J. The applications of qualitative methods to social research. In: RITCHIE, J.; LEWIS, J. (Ed.). Qualitative research practice: a guide for social science students and researchers. London: Sage Publications, 2003. p. 24-46.

SCHERER, A.G.; STEINMANN, H. Some remarks on the problem of incommensurability in Organization Studies. Organization Studies, v. 20, n. 3, p. 519-544, 1999.

SERVA, M. O paradigma da complexidade e a análise organizacional. Revista de Administração de Empresas, São Paulo, v. 32, n. 2, p. 26-35, abr./jun. 1992.

SOUZA, D.V.; ZIONI, F. Novas perspectivas de análise em investigações sobre meio ambiente: a teoria das representações sociais e a técnica qualitativa da triangulação de dados. Saúde e Sociedade (On-line), v. 12, n. 2, p. 76-85, 2003. Disponível em:<www.scielo.br/pdf/sausoc/v12n2/08.pdf>. Acesso em: 18 jun. 2009.

SNAPE, D.; SPENCER, L. The foundations of qualitative research. In: RITCHIE, J.; LEWIS, J. (Ed.). Qualitative research practice: a guide for social science students and researchers. London: Sage Publications, 2003. p. 1-23.

SZCZEPANIK, G.E. A linguagem paradigmática da ciência. In: SEMINÁRIO INTERNACIONAL SOBRE FILOSOFIA E EDUCAÇÃO: RACIONALIDADE, DIVERSIDADE E FORMAÇÃO PEDAGÓGICA, III. Anais... Passo Fundo: Editora Universitária UPF, 2008. 
TADAJEWSKI, M. The debate that won't die? Values incommensurability, antagonism and theory choice. Organization, v. 16, p. 467-485, Jul. 2009.

TEDDLIE, C.; TASHAKKORI, A. Major issues and controversies in the use of mixed methods in the social and behavioral sciences. In: TASHAKKORI, A.; TEDDLIE, C. (Ed.). Handbook of mixed methods in social and behavioral research. Thousand Oaks: Sage, 2003.

TEIXEIRA, J.C.; ANTONIALLI, L.M.; NASCIMENTO, M.C.R. Perfil de estudos em administração que utilizaram triangulação metodológica: uma análise dos anais do EnAnpad de 2007 a 2009. In: SEMINÁRIO EM ADMINISTRAÇÃO, XIII, São Paulo, 2010. Anais... São Paulo: USP, 2010.

TEIXEIRA, J.C.; NASCIMENTO, M.C.R. Uma defesa à triangulação metodológica e ao multiparadigmatismo nas pesquisas em contraposição a resistências enfrentadas: uma análise dos anais do EnAnpad de 2009. In: ENCONTRO NACIONAL DA ANPAD, XXXIV, Rio de Janeiro, 2010. Anais... Rio de Janeiro: Anpad, 2010.

TEIXEIRA, J.C.; NASCIMENTO, M.C.R.; ANTONIALLI, L.M. A triangulação metodológica na divisão de Administração Pública e Gestão Social do EnAnpad: analisando a área mais representativa entre os estudos que utilizaram a triangulação nos anais de 2007 a 2009. In: ENAPG, Vitória, 2010. Anais... Rio de Janeiro: Anpad, 2010.

VERGARA, S.; CALDAS, M. Paradigma interpretacionista: a busca da superação do objetivismo funcionalista nos anos 1980 e 1990. Revista de Administração de Empresas, v. 45, n. 4, p. 66-72, 2005.

WILLMOTT, H. Breaking the paradigm mentality. Organization Studies, v. 14, n. 5, p. 681-720, 1993.

WRIGHT, J.T.C.; GIOVINAZZO, R.A. Delphi — uma ferramenta de apoio ao planejamento prospectivo. Caderno de Pesquisas em Administração, São Paulo, v. 1, n. 12, 2. trim. 2000.

Juliana Cristina Teixeira é doutoranda em administração pelo Centro de Pós-Graduação e Pesquisas em Administração da Universidade Federal de Minas Gerais (Cepead/UFMG). E-mail: julianacteixeira@ yahoo.com.br.

Marco César Ribeiro Nascimento é bacharel em administração pela Universidade Federal de São João del-Rei (UFSJ). E-mail: marcocesar82@hotmail.com.

Alexandre de Pádua Carrieri é professor associado do Departamento de Ciências Administrativas e do Cepead da UFMG. E-mail: alexandre@face.ufmg.br. 